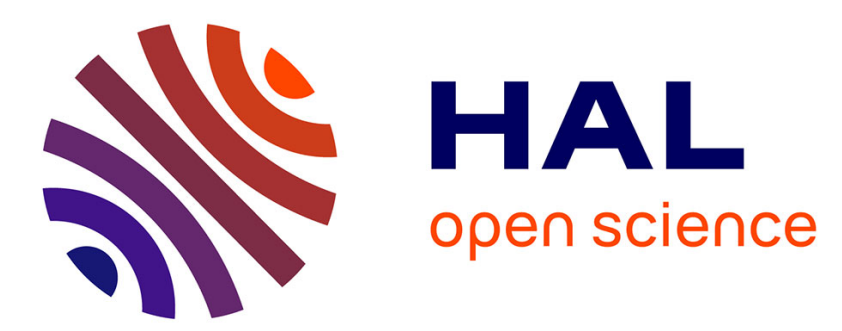

\title{
THE ELECTRONIC AND OPTICAL PROPERTIES OF VANADIUM TELLURITE GLASSES
}

B. Flynn, A. Owen

\section{To cite this version:}

B. Flynn, A. Owen. THE ELECTRONIC AND OPTICAL PROPERTIES OF VANADIUM TELLURITE GLASSES. Journal de Physique Colloques, 1981, 42 (C4), pp.C4-1005-C4-1008. 10.1051/jphyscol:19814219 . jpa-00220848

\section{HAL Id: jpa-00220848 https://hal.science/jpa-00220848}

Submitted on 1 Jan 1981

HAL is a multi-disciplinary open access archive for the deposit and dissemination of scientific research documents, whether they are published or not. The documents may come from teaching and research institutions in France or abroad, or from public or private research centers.
L'archive ouverte pluridisciplinaire HAL, est destinée au dépôt et à la diffusion de documents scientifiques de niveau recherche, publiés ou non, émanant des établissements d'enseignement et de recherche français ou étrangers, des laboratoires publics ou privés. 


\title{
THE ELECTRONIC AND OPTICAL PROPERTIES OF VANADIUM TELLURITE GLASSES
}

\author{
B.W. Flynn and A.E. Owen \\ Department of Electrical Engineering, University of Edinburgh, King's \\ Buizdings, Edinburgh EHg $3 J L$, Scotzand, U.K.
}

Abstract. Data are presented on the d.c. conductivity, thermopower and optical absorption of vanadium tellurite glasses, particularly as a function of the ratio $\left(v^{4+} / V_{\text {total }}\right)$. The results are interpreted in terms of polaron theory and comparisons made with other data. Differences and similarities are noted.

Introduction. Preliminary data on the electronic properties of $\mathrm{V}_{2} \mathrm{O} 5-\mathrm{X} \cdot \mathrm{TeO}_{2} \mathrm{~g} 1 \mathrm{lasses}$ have already been reported (1) and recently Isard (2) has suggested that the electronic behaviour of these glasses corresponds more closely with simple polaron theory than any other transition metal oxide glass. This paper reports further measurements on the vanadium tellurite glass system. Glasses were prepared at intervals of 10 mole $\%$ between $10 \%$ and $50 \% \mathrm{~V}_{2} 05$, by melting at approximately $900^{\circ} \mathrm{C}$ and quenching by pouring the melts onto a metal plate at room temperature. To control the valence ratio $\left[\left(V^{4+} / V_{\text {Total }}\right)=c\right]$, the glasses were either melted in air at slightly different temperatures or elemental Te was added to the melt. After annealing at $250^{\circ} \mathrm{C}$ for 2 hours, samples were ground and lapped to give discs of about $1 \mathrm{~cm}$ in diameter and $7-2 \mathrm{~mm}$ thick. Gold was deposited onto the flat faces of the discs to provide contacts for electrical measurements. Analysis of the valence ratio (c) was carried out by chemical and colorimetric methods. Optical measurements were made with a Zeiss spectrophotometer, generally using thin glass samples prepared by breaking pieces from bubbles blown from molten glass.

D.C. Conductivity. Previous work (1) has shown that above about $200 \mathrm{~K}$ the d.c. conductivity of vanadium tellurite glasses follows the usual activated form

$$
\sigma=\sigma_{0} \exp (-W / k T)
$$

with a constant activation energy, $\mathrm{H}$, while below $200 \mathrm{~K} \mathrm{~W}$ decreases continuously. This behaviour can be explained in general terms by the thermally activated hopping of small polarons in a disordered structure. In the high temperature regime $(T \geqslant 200 \mathrm{~K})$ the activation energy is constant and probabiy arises from the hopping of carriers plus a contribution ( $\left.\frac{1}{2} \mathrm{H}_{0}\right)$ from the structural disorder energy, $W_{0}$. At temperatures below $200 \mathrm{~K}$ there is a progressive reduction in the activation energy as expected from the continuous reduction in available phonon energy.

Conduction in transition-metal oxides may be described by the expression proposed by Mott (3) for conduction by hopping between localised states, i.e.

$$
\sigma=v_{0}\left(n e^{2} a^{2} / k T\right)[c(1-c)] \exp (-2 a a) \exp (-W / k T)
$$

where $v_{0}$ is a phonon frequency, $n$ is the number of transition metal ion sites, is 
the site separation and $\alpha$ is a tunnelling factor. From density and composition data numerical values for the second and third terms in equation 2 can be calculated and knowing $\sigma_{0}$ in equation $l$, values of $v_{0} \exp (-2 a a)$, the number of site transitions which a carrier makes per second, may be determined. An estimate of $\alpha$ and $\nu_{0}$ can be made from Figure $l$ in which $\log \left[\nu_{0} \exp (-2 \alpha a)\right]$ is plotted versus $a$, the site spacing. From the slope of this graph $\alpha \sim 0.097 \mathrm{~m}^{-1}$, in good agreement with data given by Austin and Garbett (4), and $v_{0} \sim 6 \times 10^{13} \mathrm{~s}^{-1}$.

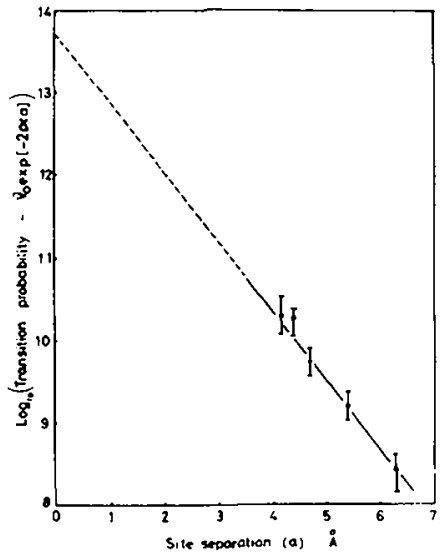

Fig. I Carrier transition probability Fig. 2 versus site spacing.

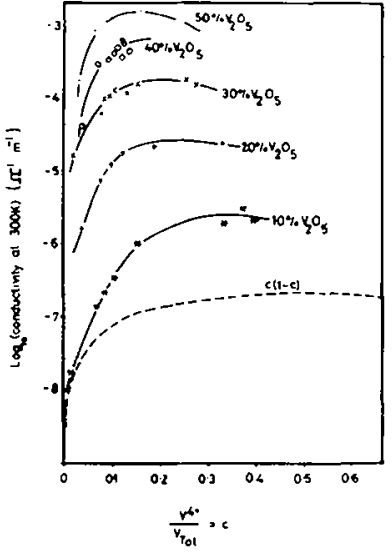

Conductivity as a function of the valence ratio ( $\left.V^{4+} / V_{T o t a l}\right)$, for different total $\mathrm{V}_{2} \mathrm{O}_{5}$ contents (mole $\%$ ).

The bars in Figure 3 indicate the spread caused by the different valence ratios, $c$, of the different glasses. One feature worthy of note is that the tunnelling factor (and site spacing) is obviously very significant in the tellurite glasses, in marked contrast to the phosphate glasses where no dependence of conductivity on site spacing is observed (5). This analysis assumes that the phonon frequency is independent of site spacing but Sayer and Mansingh (5) found that it decreases as the site spacing is reduced. If this is also the case for tellurite glasses the estimate of the phonon frequency would be lowered from the rather high value of $6 \times 10^{13} \mathrm{~s}^{-1}$. The reasons why tellurite glasses should be different from phosphate glasses in this respect are not obvious. One possibility is that Te sites can participate in the conduction process to a limited extent. TelTurium may exist in the valence states $\mathrm{Te}^{2-}$ and $\mathrm{Te}^{6+}$ as well as $\mathrm{Te}^{4+}$. In the process of melting it is likely that a small proportion of the $\mathrm{Te}_{2}$ is oxidised either by reaction with atmospheric oxygen above the melt or by reaction with $\mathrm{V}_{2} \mathrm{O}_{5}$. Under these conditions charge transfer couid also occur between $T e$ ions or between Te and $V$ ions, enabling additional charge transfer processes.

The dependence of the conductivity on the valence ratio $c$ is shown in Figure 2 where the conductivity at $300 \mathrm{~K}$ is plotted as a function of $\mathrm{c}$ for different total vanadium concentrations. The conductivity increases with increasing $v^{4+}$ content until $c \approx 0.2$ after which the curves level out and shown signs of a gradual decrease at higher $\mathrm{V}^{4+}$ concentrations. Theories of hopping conduction in mixed valence semiconductors predict a conductivity maximum when there are equal numbers of 
occupied and unoccupied sites i.e. when $c=0.5$. In the vanadium phosphate glass system Linsley (6) found a well defined maximum in conductivity at $c \simeq 0.2$ and this discrepancy between theory and experiment has also been observed by other workers $(7,8,9)$. Three explanations have been advanced; ( $i)$ that a portion of the $v^{5+}$ ions are bound in structural complexes and are unable to participate in the conduction process ( 7 ), ( $i$ ) Kinser and Wilson (8) have suggested that the conductivity maximum at $c \simeq 0.2$ is caused by the formation of a homogeneous glass structure around this value, (iii) glass - glass phase separation occurs with one phase containing all of the $v^{4+}$ ions while the other phase has only $v^{5+}$ ions (9). Information on the structural properties of $\mathrm{V}_{2} \mathrm{O}_{5}-\mathrm{Te}_{2}$ glasses is scanty, but the formation of large vanado-tellurite complexes seems less likely than the formation of vanadophosphate complexes in $\mathrm{V}_{2} \mathrm{O}_{5}-\mathrm{P}_{2} \mathrm{O}_{5}$ glasses.

Thermopower. The thermopower (S) was measured and in the range $290 \mathrm{~K}$ to $400 \mathrm{~K}$ it is virtually independent of temperature. Generally the thermopower becomes smaller on reducing the $\mathrm{V}_{2} \mathrm{O}_{5}$ content of the glass, probably in part because the ratio $\mathrm{C}$ increases as the vanadium content of the glass decreases. The results of the room temperature measurements of thermopower for glasses of different compositions are plotted in Figure 3 as a function of the ratio c. Also shown in this graph is a dotted line corresponding to the equation proposed by Heikes and Ure (10) for the thermopower in narrow-band semiconductors, i.e.

$$
S=(k / e)\left[\left(\Delta S_{R} / k\right)+\ln \{c /(1-c)\}\right]
$$

but assuming that the entropy term $(\Delta S / K)$ is negligibly small. Heikes and Ure (10) do not define the term $(\Delta S / k)$ but Austin and Mott (11) suggest that it has a value between 0.1 and 0.2 and consequently can be neglected. The experimental results do not agree well with values of S calculated from equation 3 but note that $S=0$ when $C \sim 0.2$ which is the same ratio at which the conductivity goes through a maximum. Similar arguments are applicable to the variation of the thermopower with valence ratio as were applied to the conductivity.

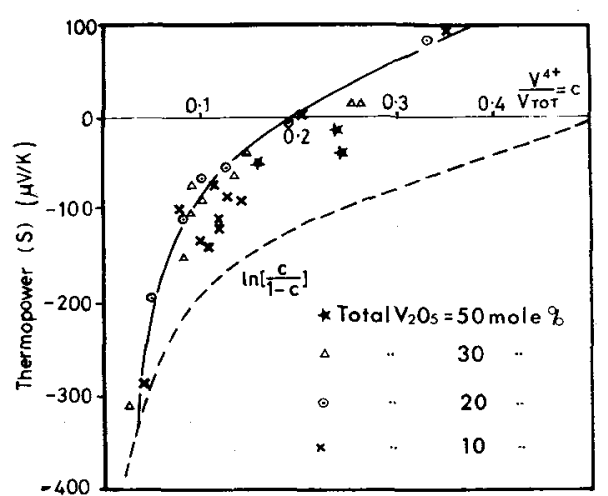

Vonadium valence ratio (c)

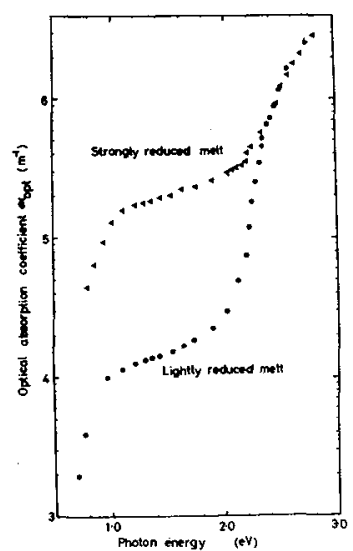

Fig. 4 Optical absorption versus photon energy for two glasses containing 60 mole $\% v_{2} 0_{5}$, but differing degrees of reduction, i.e. different $\left(V^{4}+/ V_{\text {Total }}\right)$ ratios. 
Optical Absorption. Optical absorption measurements were made as a function of photon energy at room temperature $(\sim 300 \mathrm{~K})$ and $77 \mathrm{~K}$, and a steep absorption edge is observed for each glass at about 2.2 to $2.4 \mathrm{eV}$, at room temperature, with a small shift of about $0.05 \mathrm{eV}$ to higher energies on lowering the temperature to $77 \mathrm{~K}$. The position of the edge at $2.2 \mathrm{eV}$ was found to be independent of total vanadium content and the percentage of reduced vanadium, supporting the conclusion that the fundamental edge is the result of direct forbidden transitions between the oxygen $2 p$ bands and the vanadium $3 \mathrm{~d}$ band of the $\mathrm{V}_{2} \mathrm{O}_{5}$. Further support for this view is supplied by the optical absorption of crystalline $\mathrm{V}_{2} \mathrm{O}_{5}$. Kenny et al (12) measured the absorption coefficient in $\mathrm{V}_{2} \mathrm{O}_{5}$, along the different crystal axes, and found, for each, a fundamental absorption edge increasing from $2.2 \mathrm{eV}$, which they attribute to direct forbidden transitions.

The absorption of glasses of the composition $\left(\mathrm{V}_{2} \mathrm{O}_{5}\right)_{40}\left(\mathrm{TeO}_{2}\right)_{60}$ was studied at low values of $\alpha_{\text {opt }}$ in the region of the absorption taif in order to observe the effects of varying the ratio $c$ and typical results are shown in Figure 4 . At the lower end of the absorption curve a shoulder appears which increases in intensity as the vanadium is progressively reduced. This shoulder is interpreted as being the combination of a broad absorption band and the tail of the absorption edge. Small polaron theory predicts (11) a series of absorption lines at multiples of twice the polaron binding energy $\left(W_{p}\right)$, which are broadened by thermal motion of the lattice, resulting in a series of Gaussian absorption peaks. This absorption arises from the optical excitation of a carrier from its polarisation well and subsequent transfer to another lattice site, corresponding, in a vanadate glass, to the transfer of an electron from a $V^{4}+$ site to a $V^{5+}$ site. In the vanadate glasses it is only possible, in practice, to observe the first absorption peak since the fundamental absorption edge arising from the $2 p$ and $3 d$ direct forbidden transitions of the $\mathrm{V}_{2} \mathrm{O}_{5}$ masks the higher order peaks.

The position of the polaron absorption peak can be related to the d.c. conductivity and the thermopower data through hv $=E_{\text {opt }}=2 \mathrm{Wp}$ where $E_{\text {opt }}$ is the incident photon energy and $w_{p}$ is the polaron binding energy. The polaron binding energy is related to the hopping energy $W_{H}$ by (11) $W_{H}=\frac{1}{2} W_{p}$. Therefore, hv $=E_{\text {opt }}=4 \mathrm{WH}$. But $W_{H}=\left(W-\frac{1}{2} W_{D}\right)$ where $W$ is the conduction activation energy and $W_{D}$ is the disorder energy. Typically for a 40 mole $\% V_{2} 05 \mathrm{glass} W$ is $0.28 \mathrm{eV}$ and the thermopower data gives a value of $0.02 \mathrm{eV}$ for $W_{D}(1)$. Thus, E $E_{\text {opt }} \simeq 1.1 \mathrm{eV}$. This agrees well with the position of the shoulder in the absorption edge indicating a polaron binding energy of $0.6 \mathrm{cV}$. It is reasonable, therefore, to interpret the shoulder in terms of polaron hopping but the present evidence is not sufficient to discount the possibility of it arising from an internal d-d excitation of electrons in the vanadium atoms.

\section{References}

1. FLYNN, B.W., OWEN, A.E. and ROBERTSON, J.M. Proc. 7 th Int. Conf. Amorphous and Liquid Semiconductors, (CICL, Univ. of Edinburgh), (1977), 678.

2. ISARD, J.0. J. Non-cryst. Sol. 42, (1981), 371.

3. MOTT, N.F. J. Non-cryst. Sol. I, (1968), i.

4. AUSTIN, I.G. and GARBETT, E.S. "Electronic and Structural Properties of Amorphous Semiconductors" Editors: LeComber, P.G. and Mort, J. (Academic Press), (1973), 393.

5. SAYER, M. and MANSINGH, A. Phys. Rev. B6, (1972), 1629.

6. LINSLEY, G.S. "Electronic Conduction in Vanadate Glasses" (Ph.D. Thesis, Sheffield Univ.) (1968).

7. LINSLEY, G.S., OWEN, A.E. and HAYATEE, F.M. J. Non-cryst. Sol. 4, (1970), 208.

8. KINSER, D.L. and U!ILSON, L.K., Proc. 2nd Cairo Solid State Conf. (1973).

9. BOGOMALOVA, L.D. et al. Sov. Phys. Sol. State $16,(1974), 5$.

10. HEIKES, R.R. and URE, R. "Thermoelectricity : Science and Engineering" (Interscience) (1961), Chapter 4.

11. AUSTIN, I.G. and MOTT, N.F. Adv. in Phys. 18, (1969), 41.

12. KENNY, N., KANNEHURF, C.R. and HHITMORE, D.H. J. Phys. Chem. 27, (1966), 1237. 